MUSICA THEORICA 2021, V. 6.1

SCIENTIFIC ARTICLE

DOI: $10.52930 / \mathrm{mt} . v 6 \mathrm{i} 1.181$

Data do recebimento: 30/08/2021

Data da aprovação final: 01/10/2021

\title{
Aspectos técnicos, estéticos e composicionais em Graphein de Raphael Cendo
}

\author{
Technical, Aesthetic, and Compositional Aspects in Graphein by Raphael \\ Cendo
}

\author{
Sergio Kafejian \\ Faculdade Santa Marcelina \\ Silvio Ferraz \\ Universidade de São Paulo
}

\begin{abstract}
Resumo: Dentre as correntes estéticas da música de concerto que surgiram no início do Século XXI, o Saturismo se destaca tanto por propor novos modelos de organização do material sonoro quanto por dar continuidade à pesquisas de sonoridades que vinham se desenvolvendo na música de tradição escrita desde os anos de 1960. Nesse artigo, buscaremos compreender quais são os recursos técnicos e os preceitos estéticos que sustentam a obra Graphein (2014) de Raphael Cendo, um dos principais compositores dessa corrente estética. Para tal, na primeira parte do artigo, iremos contextualizar historicamente o surgimento do Saturismo; na segunda iremos expor os principais conceitos e técnicas elaboradas no Saturismo; e para finalizar, apresentaremos uma proposta de análise das forças de organização que determinam o desenvolvimento de Graphein. A metodologia utilizada na análise consistiu no aprofundamento das ideias conceituais e das ferramentas composicionais do Saturismo através da leitura de textos e transcrição de entrevistas; análise da partitura; análise do fonograma - a partir dos conceitos de análise aural de Lasse Thoresen -; e análise do fonograma a partir de descritores de áudio.
\end{abstract}

Palavras-chave: Técnicas estendidas. Saturismo. Graphein. Raphael Cendo. Descritores de áudio.

Abstract: Among the aesthetic currents of concert music that emerged at the beginning of the 21st century, Saturism stands out for proposing new models of organizating the sound material and for continuing the research on sounds that had been developing in traditional written music since the years of 1960. In this article, we will seek to understand the technical resources and aesthetic precepts that support the work Graphein by Raphael Cendo, one of the main composers of this aesthetic current. To this end, in the first part of the article, we will historically contextualize the emergence of Saturism; in the second, we will expose the 
MUSICA THEORICA Revista da Associação Brasileira de Teoria e Análise Musical 2021, v. 6, n. 1, p. 192-217 - Journal of the Brazilian Society for Music

main concepts and techniques developed in Saturism; and finally, we will present a proposal to analyze the organizational forces that determine the development of Graphein. The methodology used in the analysis consisted of deepening the conceptual ideas and compositional tools of Saturism through the reading of texts and transcription of interviews; score analysis; analysis of the phonogram - based on the aural analysis concepts, proposed by Lasse Thoresen -; and analysis of the phonogram using audio descriptors.

Keywords: Extended Techniques. Saturism. Graphein. Raphael Cendo. Audio Descriptors.

\section{Introdução ${ }^{1}$}

Dentre as principais transformações ocorridas nos processos composicionais dos últimos cinquenta anos, a apropriação e formalização do uso das sonoridades advindas das técnicas estendidas possuem um lugar de destaque, sendo responsáveis por desencadear sensíveis transformações nos processos de elaboração da música de concerto. A partir da segunda metade dos anos de 1960, obras de compositores como Helmut Lachenmann e Salvatore Sciarrino já propunham modelos de organização musical não mais calcados na hierarquização dos sons de alturas definidas. Contrariamente, eram as instabilidades e ruidosidades dos sons advindos do uso de técnicas instrumentais estendidas ${ }^{2}$ - assim como as próprias mecanicidade e fisicalidade presentes em tais técnicas -, que condicionavam os modelos de organização do discurso composicional de ambos os autores. Como consequência de tal direcionamento, o período localizado entre o fim dos anos de 1960 e a década dos anos de 1970 viu surgir toda uma série de novas técnicas de produção sonora nos instrumentos acústicos e uma grande proliferação de novos timbres e maneiras de tocar passaram a fazer parte do repertório dos intérpretes e compositores (Solomos 2013, p. 94) ${ }^{3}$.

\footnotetext{
${ }^{1}$ Agradecimentos à Fundação de Amparo à Pesquisa do Estado de São Paulo/FAPESP pelo apoio à pesquisa dos autores, proc. ํㅡㄹ 2015/20236-4.

2 Entendemos por técnicas instrumentais estendidas aquelas que produzem sonoridades que fogem do escopo das sonoridades advindas das técnicas usadas no jogo instrumental clássicoromântico, e mesmo do último barroco, centradas na clareza da nota musical de altura definida e dos objetos musicais a essas relacionadas, como as estruturas melódicas e harmônicas.

${ }^{3}$ Desde o final dos anos 1960 o já comum manual de extensões técnicas, como proposto por Bruno Bartolozzi, torna-se regra e surgem diversos livros dirigidos a instrumentistas com amplo mapeamento das extensões técnicas instrumentais. Distinguiríamos aqui as extensões no âmbito das alturas (modos de produção de intervalos infracromáticos) e as técnicas de controle de
} 
É importante ressaltar que tais investigações sonoras estavam atreladas tanto a pesquisas mais formalizadas, como as realizadas pelos compositores espectrais, quanto a pesquisas ligadas a movimentos mais independentes como os grupos ligados às artes performáticas e conceituais - decorrentes das propostas de compositores como John Cage, Cornelius Cardew, Earle Brown -; ou ainda ligadas aos movimentos da chamada improvisação livre e da música intuitiva ${ }^{4}$. Essas novas práticas musicais desencadearam diversas mudanças no sistema de notação musical, que passaram a contar com a presença cada vez maior de partituras abertas, partituras gráficas e partituras prescritivas, trazendo para o universo da notação musical aspectos advindos diretamente da performance musical como: novas concepções temporais, novos modos de jogo instrumental, novos modelos gestuais. Outros fatores importantes nesse processo foram os novos anseios e necessidades de compositores que se viam face a sonoridades que não estavam compreendidas no universo sonoro herdado diretamente da prática clássico-romântica -, e que passaram a ter, com as os novos dispositivos de digitalização do som, ferramentas de análise e tratamento dos dados espectrais do som.

Passado mais de cinquenta anos da produção das primeiras obras que fizeram uso ostensivo das técnicas e sonoridades estendidas, pode-se verificar que uma importante parte da produção musical contemporânea ainda tem como foco a investigação das organizações sonoras que fazem uso de tais sonoridades e técnicas. A esse respeito afirma Solomos:

No domínio da música contemporânea, as pesquisas sobre o timbre (modos de tocar) e/ou na linha de um Lachenmann - sobre a "música concreta instrumental", diminuíram consideravelmente, a partir dos anos 1980, o fosso entre som "musical" e ruído: esse trabalho refinado sobre outras qualidades do som que não a altura, acabou por convencer o auditor que a

produção de ruídos coloridos diversos. Destacam-se uma série de manuais surgidos entre os anos 1980 e 1990, como os propostos por instrumentistas como Pierre Ives Artaud, Stuart Dempster (a quem Berio dedica sua Sequenza para trombone), Fritz Dolak e Henry Boch, Sergio Penazzi, Peter Veale e Jean-Pierre Robert, e livros que buscam repensar o quadro completo dos instrumentos como os de Gardiner Reads e o grande livro de orquestração de Walter Gieseler, Luca Lombardi e Rolf-Dieter Weyer.

${ }^{4}$ A música intuitiva foi proposta por Karlheinz Stockhausen nos anos de 1960 e buscava trazer para o campo da música de concerto práticas de criação fundadas em processos que transcendiam o racionalismo assim como as práticas interpretativas baseadas exclusivamente em partituras tradicionais. Cf. Cott (1973); Stokhausen (1989); Stokhausen; Maconie (2000). 
MUSICA THEORICA Revista da Associação Brasileira de Teoria e Análise Musical 2021, v. 6, n. 1, p. 192-217 - Journal of the Brazilian Society for Music

desaparição relativa desta última não significa necessariamente que nós estamos na presença de um ruído, no sentido de um incômodo (Solomos 2013, p. 101).

Compositores como Clara Iannota (Itália), Julien Malaussena (França), Ashley Furer (EUA) Danniel Ribeiro e Michelle Agnes (Brasil) são exemplos de novos compositores e compositoras cujas obras se elaboram tendo como fator determinante a investigação de novos timbres, sonoridades e modos de execução.

$\mathrm{Na}$ obra desses autores e autoras, podemos constatar que não só as técnicas estendidas tradicionais - essas surgidas entre os anos de 1960 e 70 continuam pertinentes para os processos criativos da atualidade, como novos timbres e modos de execução continuam a ser criados pelos compositores, compositoras e instrumentistas. Dentro do escopo dessas novas investigações, que visam expandir ainda mais as paletas sonoras e as técnicas de execução dos instrumentos acústicos, podemos notar um grande interesse na transformação física do próprio instrumento, seja através do acoplamento de objetos a corpos ressonadores, cordas, cavaletes, bocais, seja através do uso de objetos não usuais nos processos de excitação do instrumento. Alguns exemplos de tais procedimentos são a inserção de objetos de metal entre as cordas de um violino; a execução do piano através da excitação direta das cordas feitas por fios de nylon, cordas de guitarra ou plectros de metal; ou ainda, a inserção de folhas de papel alumínio em instrumentos com a trompa ou o trompete ${ }^{5}$.

No entanto, se as novas sonoridades e técnicas instrumentais transformaram radicalmente a matéria sonora a partir da qual se dão os processos de elaboração composicional, esta nova matéria, por sua vez, transformou os paradigmas de organização musical da música de concerto. Pois, como afirma Solomos: "a exploração dos sons de altura indeterminada não somente enriqueceu o material musical, mas, dito de outra forma, transforma nossa concepção mesma da música" (Solomos 2013, p.11). Dentro desse cenário, uma corrente estética musical se destacou, tanto por aportar postulados estéticos,

\footnotetext{
${ }^{5}$ Quanto a estes aspectos citamos aqui como importantes referências de tais transformações o livro Compendium of Modern Instrumental Techniques, de Gardner Read (1998) e o grande tratado de instrumentação de Gieseler, Lombardi e Weyer (Instrumentation in des 20 Jahrhunderts. 1985), além de outros estudos que enfocam os instrumentos musicais do ponto de vista de suas características acústicas como os estudos de Jürgen Meyer publicados em artigos e posteriormente em livro, em 2009. (Acoustics and the performance of music).
} 
técnicos e filosóficos, quanto por produzir obras de referência, essa corrente foi designada por Saturismo.

\section{Saturismo}

Dentre as correntes estéticas surgidas a partir dos anos 2000, o saturismo ${ }^{6}$ se destaca por fundamentar seus processos criativos na exploração dos sons instáveis e ruidosos advindos das técnicas estendidas. Tratava-se não de incorporar o ruído, estratégia que remonta aos primeiros anos do século $X X$, mas de integrar os fenômenos complexos como ponto de partida para pensar tanto a forma quanto o uso dos instrumentos ${ }^{7}$. Para os compositores envolvidos com o surgimento dessa corrente composicional, a principal questão centrava-se na "maneira de integrar ao discurso musical os fenômenos complexos, colocandoos no centro de sua prática" (Cendo 2011). Conceitos como os de dissolução sonora, mistura de timbre, acumulação, poluição, saturação pelo ruído, passaram a nortear os processos de elaboração desses compositores. Para Raphael Cendo - um dos principais expoentes desta corrente estética, juntamente com Frank Bedrosian -, o saturismo soube "encontrar uma gramática, uma linguagem e os materiais que lhe são próprios" (ibid. 2010), instaurando novos paradigmas de agenciamento do material sonoro.

Se a música de concerto esteve, até o fim do século $X X$, predominantemente atrelada a uma elaboração musical "que se organizou em torno de um pensamento controlado, paramétrico e microscópico da escritura" (ibid.), o saturismo centra suas pesquisas em sons cujas complexidade e ambiguidade escapam às principais ferramentas de análise e controle do pensamento musical até então dominante. Para o compositor francês, "os poderes evocatórios [dos sons complexos], muito poderosos em sua expressão,

\footnotetext{
${ }^{6} \mathrm{O}$ conceito de saturação vem emprestado tanto do campo da física - no qual saturar significa combinar, misturar ou dissolver excessivamente -, quanto do campo da música eletrificada, no qual a saturação resulta da amplificação excessiva de um sinal sonoro, indo além do limite do sistema de gravação ou amplificação desse mesmo sinal.

7 O Saturismo se apropria e leva adianta diversos conceitos e técnicas presentes na Música Espectral, corrente estética que já fundava suas propostas poéticas na apropriação dos sons enquanto fenômenos complexos. No entanto, contrariamente à corrente espectral, que trabalhava e elaborava seus discursos a partir das análises dos espectros sonoros e suas evoluções (Murail 1992), o Saturismo trabalha, como veremos, a partir da exterioridade dessas sonoridades assim como na gestualidade e energia dos jogos instrumentais.
} 
MUSICA THEORICA Revista da Associação Brasileira de Teoria e Análise Musical 2021, v. 6, n. 1, p. 192-217 - Journal of the Brazilian Society for Music

não correspondiam aos desejos estéticos nem ao grilhões da justificação analítica próprios do século XX" (ibid.), pois "a música saturada, em seus excessos, revela dimensões que estavam mascaradas, revela um mistério que nos escapa: nos seus campos de força, a música saturada ritualiza" (ibid.). Sendo assim, o saturismo se coloca enquanto uma poética que recusa o gesto "domesticado" e "civilizado", o artefato e o artificio, privilegiando a busca de um gesto bruto, selvagem, "um excesso de matéria, de energia, de movimentos e de timbre" (ibid. 2008), sobrepujando aos limites o jogo instrumental assim como as capacidades físicas e mecânicas do intérprete. A esse respeito, escreve o compositor francês: "a saturação é, portanto, a recusa do controle absoluto, e se torna uma busca da animalidade como rejeição da domesticação como desejo de constituir novos territórios" (ibid.).

\subsection{Escrita e escritura na música "saturada"}

Ao escolher os sons complexos ${ }^{8}$ e ruidosos, o saturismo opta por abrir mão do controle e do domínio, em nível microscópico, do discurso musical. A variabilidade e inconstância dessas sonoridades, conjugadas com os excessos de gestos, dinâmicas e técnicas instrumentais estendidas acabam por colocar constantemente em cheque o controle, tanto do compositor - em seus processos de escritura -, quanto do intérprete - em seus atos interpretativos -, sobre o material musical. Para o intérprete, não se trataria mais de representar, mas de agir, pois "comumente essas obras lhes propõem tornarem-se atores e não mais representantes de uma obra" (ibid. 2010). Para os compositores, trata-se de atuar em um nível da elaboração musical que os saturistas chamam de macro escritura. Assim afirma Cendo:

a primeira ruptura imposta pela saturação instrumental se dá através de uma mudança no campo da escritura, permitindo a utilização dos fenômenos saturados e a perda de controle na interpretação. Nós passamos de uma micro precisão a uma macro escritura, isto quer dizer, a uma representação

\footnotetext{
8 O conceito de som complexo pode ser entendido dentro do que Tristan Murail classificou como: "os novos materiais que estão à disposição do compositor [...] sejam eles de origem instrumental ou elétrica. Trata-se muitas vezes de sons complexos, sons intermediários, mistos, sons que possuem novas dimensões (transitórios, evolução no tempo, ...), sons que não são nem complexos harmônicos, nem timbres, mas alguma coisa entre os dois" (Murail 1992).
} 
simbólica menos constritora do fenômeno sonoro, nós alargamos a possibilidade de utilização do timbre (Cendo 2010).

Destarte, a escritura "saturada" acaba por ampliar o campo da escrita tradicional, fazendo com que essa passe a comportar os sons de características acústicas não redutíveis a frequências e comportamentos rítmicos unívocos, sem, no entanto, perder sua capacidade de projetar o ordenamento dos eventos nos espaços frequencial e temporal. Para tal, os saturistas conjugam elementos da escrita gráfica e prescritiva ${ }^{9}$, associando-os com os recursos do sistema de notação tradicional - já acrescidos de toda a nova simbologia surgida nos anos de 1960 e 1970 através das obras de compositores como Helmut Lachenmann, Salvatore Sciarrino, Gerard Grisey, Tristan Murail, entre outros.

Ao propor a ideia de macro escritura, esse compositores propõem substituir o excesso de detalhes da notação - que passaram a dominar as partituras a partir de meados dos anos de 1950 -, por uma notação mais global, no qual o foco está antes em descrever as ações enquanto gestos complexos do que em representar os resultados sonoros decorrentes de tais gestos. Não é mais o som que está sendo representado na escrita, mas toda uma série de ações que produzem sons cujas complexidade e instabilidade não podem ser reduzidas aos elementos rítmico-frequenciais característicos dos sons representados pela notação tradicional.

Para compreendermos como essa escrita "estendida" opera, iremos abordar três exemplos de notação de gestos, assim como aparecem na bula de Graphein.

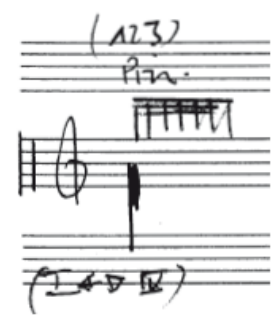

Exemplo 1: Notação de gesto referente aos instrumentos de cordas. Extraído da obra Graphein.

\footnotetext{
9 Por notação prescritiva entendemos uma notação que "diz ao intérprete quais ações ele deve tomar frente a seu instrumento para produzir a música. O resultado sonoro será uma decorrência de tais ações" (Zampronha 2000, p. 55).
} 
MUSICA THEORICA Revista da Associação Brasileira de Teoria e Análise Musical 2021,

No Ex. 1, a notação representa o gesto de executar - nos instrumentos de cordas - pizzicatos muito rápidos, com os dedos um, dois e três, dentro do registro indicado e alternando rápida e aleatoriamente entre as cordas I, II, III e IV.

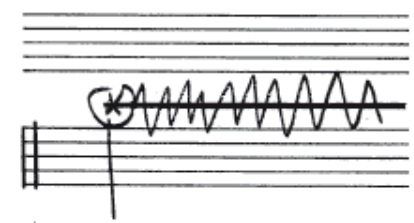

Exemplo 2: Notação de gesto referente aos instrumentos de cordas. Extraído da obra Graphein.

No Ex. 2, também referente aos instrumentos de cordas, a notação indica o gesto de esfregar os dedos sobre o espelho e as cordas, realizando movimentos curtos e rápidos. No Ex. 3, podemos verificar uma notação referente aos clarinetes e saxofones. Aqui, a notação indica a realização de um gesto composto no qual o pentagrama inferior consiste na realização aleatória, muito rápida e muito cambiante de trilos de sons fendues. Já o pentagrama superior é usado para descrever ações da voz do instrumentista, que nesse caso consiste em cantar simultaneamente, dentro do instrumento, um som no registro médio com muito vibrato.

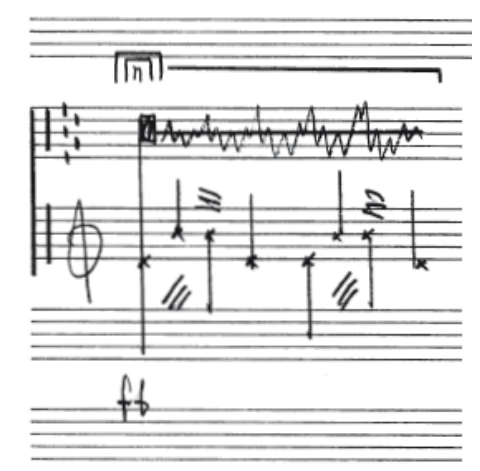

Exemplo 3: Notação de gesto referente aos clarinetes e ao saxofone. Extraído da obra Graphein.

Para finalizar, podemos verificar no Ex. 4 um excerto da obra Graphein, de Raphael Cendo, no qual elementos gráficos se associam aos recursos notacionais tradicionais. Podemos verificar que a estruturação da parte rítmica assim como os comportamentos dinâmicos são determinados pelos recursos da notação tradicional. Quanto aos comportamentos frequenciais, esses fazem uso de 
grafismos e recursos prescritivos para sugerir tanto os movimentos internos das sonoridades, quanto as transformações tímbricas desejadas pelo compositor.

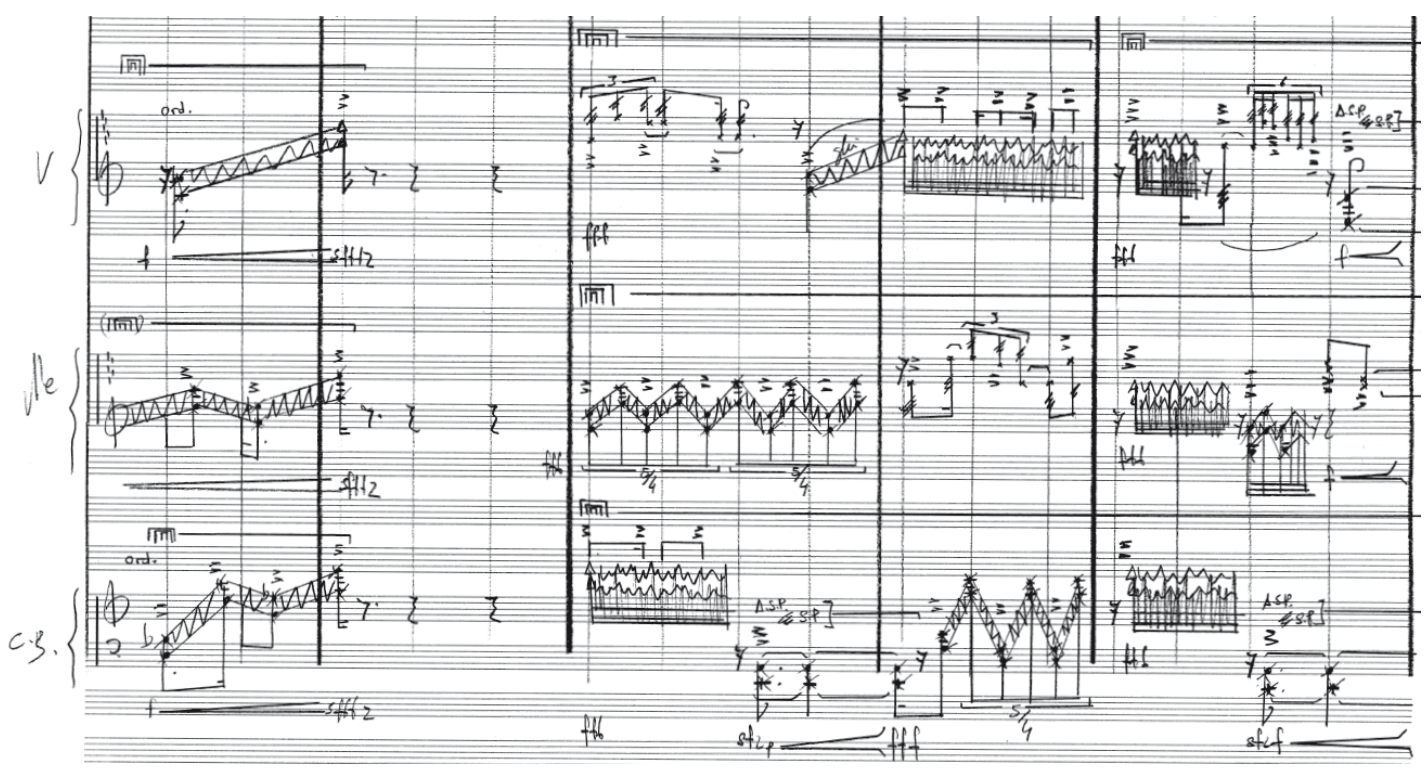

Exemplo 4: Notação de gestos referente aos violinos, viola e contrabaixo. Extraído da obra Graphein.

É certo que alguns elementos de tal expansão da escrita já podem ser verificados em obras de compositores como Hemut Lachenmann, Salvatore Sciarrino, Luciano Berio, Karlheinz Stockhausen, Krzystof Penderecki, entre outros compositores pós-seriais. No entanto, é somente com o uso excessivo de gestos, timbres complexos e sobreposições de ações - características da música saturada -, que o uso desses recursos de escrita se potencializa. Nesse novo contexto, a noção de gesto se coloca em primeiro plano, configurando-se enquanto um parâmetro fundamental da escritura musical, sobrepondo-se ao de notas e de ritmos. O gesto no saturismo torna-se o espaço no qual o movimento de energias físico-acústicas e a perda de controle instrumental levam a realização musical à um estado limite. Assim escreve Cendo:

A escritura de gestos faz apelo a outros conceitos como energia instrumental e a noção de perda de controle. O gesto dá, efetivamente, uma função capital aos movimentos, mais do que às notas, elas mesmas, mais à energia do que à afinação e à precisão. Um gesto é preciso não quando ele respeita escrupulosamente um intervalo, mas quando o movimento valoriza a energia. Nós podemos, mesmo, ir mais longe, colocando em relação o conceito de energia e a noção de perda de controle na interpretação. Nós definimos a perda de controle como um estado limite - ou catastrófico - entre o texto (a partitura) e a execução, entre o que é adquirido e o que nos escapa 
[...] para interpretar, é preciso então (ex)istir, isso quer dizer, estar fora de si, longe dos limites do jogo instrumental tradicional (Cendo 2008).

\subsection{Elaboração e organização do material}

O projeto estético saturista se completa ao propor modelos próprios de organizar e agenciar seus materiais sonoros complexos. Aqui não se trata de definir métodos, regras ou leis, mas de identificar e compreender os campos nos quais a saturação pode atuar e quais jogos de construção podem surgir da exploração dos sons complexos ${ }^{10}$.

Em um nível macroestrutural, o par de oposição da escritura que emerge é representado pelo que Raphael Cendo denominou de total saturado e infrasaturação. A primeira categoria se caracteriza pela escritura de massas sonoras potentes, dinâmicas exageradamente fortes, alta densidade de eventos e extrema fusão de timbres complexos no qual cada linha instrumental "procura seu próprio limite, gestual e dinâmico" (ibid.). Em oposição, a segunda categoria se caracteriza pela queda extrema da intensidade, pela rarefação e desdensificacão dos eventos e pelo estiramento das matérias e gestos sonoros. Quanto ao total saturado, ele é elaborado a partir de quatro instâncias, sendo elas: saturação do timbre, saturação do espaço frequencial, saturação da intensidade e saturação do gesto instrumental.

- Saturação do timbre: consiste na transformação do timbre através de novos modos de tocar que levam à produção de sons complexos. Nessa categoria de saturação estão também os sons produzidos através do acoplamento de objetos nos instrumentos - a saturação do corpo instrumental -, e a hibridização dos instrumentos. São exemplos: o uso de palhetas de oboé nos metais, o uso de objetos de metal na harpa, o uso de sordinas feitas com papel alumínio ou isopor ou fita crepe. Para Cendo, em decorrência dessa saturação, a própria escuta do instrumento se transfigura deixando de "estar unicamente centrada na 'aparelhagem' do instrumento, mas sobre sua extrapolação" (ibid.).

${ }^{10}$ É importante ressaltar que, por princípio, a estética saturista se propõe a não planificação, o abandono da noção de direcionalidade e a total ausência de um sistema. O que interessa aos saturistas são os estados sonoros instáveis, altamente reativos e de expressividades cambiante. A esse respeito Cendo ainda afirma, ao comentar sobre a elaboração de suas obras, "nós falaremos aqui de uma desorganização, de uma desorientação integral" (Cendo 2010). 
- Saturação do espaço frequencial: consiste no preenchimento total do espectro por sons complexos. A resultante sonora - ou halo sonoro -, não permite a distinção de movimentos individuais podendo mesmo ser considerada "a negação da individualidade em favor da homogeneidade" (ibid.). São características da saturação do espaço frequencial a rugosidade, a largura espectral, o grau de mistura dos timbres. São através dessas características que surgem "verdadeiros eixos de timbre nos quais uma geometria instável traça sem cessar paradoxos auditivos" (ibid.).

- Saturação da intensidade: consiste na utilização das dinâmicas extremamente fortes dos instrumentos, assim como da utilização de grandes quantidades de energia físicas dos instrumentistas. Como resultado temos projeções sonoras de intensidade "prodigiosa e insólita" permitindo uma verdadeira imersão no fenômeno sonoro, projetando o ouvinte na própria matéria do som (ibid.).

- Saturação do gesto instrumental: consiste na multiplicação de gestos instrumentais e modos de ataque diversos, rapidamente encadeados e transitando entre os instrumentos do efetivo instrumental.

Assoma-se a essas categorias conceitos como os de (1) ponto de equilíbrio efêmero - que consiste em momentos de estabilidade momentâneos como notas sustentadas ou gestos regularmente repetidos; (2) saturação do espaço frequencial pela multiplicação dos gestos: consiste na multiplicação de gestos instrumentais como col legno battuto, pizzicato, écrasé que se alternam rapidamente nos instrumentos; (3) saturação por densidade: consiste na multiplicação de gestos que se espalham velozmente no efetivo instrumental. Também é importante notar o papel primordial que os acentos e perfis dinâmicos possuem na construção das massas sonoras complexas, pois essas esculpem o deslocamento da matéria no tempo e no espaço (ibid.).

Mas se essas categorias podem ser apresentadas separadamente, elas só fazem sentido quando pensadas enquanto elementos interconectados, fusionados: "a saturação instrumental não poderia existir sem uma fusão desses diferentes parâmetros" (ibid.). Destarte, podemos compreender a morfologia na música saturada enquanto decorrência de processos de interações, emergências 
MUSICA THEORICA Revista da Associação Brasileira de Teoria e Análise Musical 2021, v. 6, n. 1, p. 192-217 - Journal of the Brazilian Society for Music

e sinergias da matéria sonora. A respeito dessa resultante de energias sonoras e físicas, os saturistas propõem o conceito de aura - ou de projeção "holográfica". Assim afirma Cendo:

A resultante das acumulações, da energia, deforma nossa percepção do sonoro. Esta aura forma um halo ajuntando assim estratos à plataforma inicial. A música saturada procura então se dar inteiramente. Através de seu desejo de tudo representar, e daí essa definição de holográfica, a música saturada em seus excessos revelam então dimensões que estavam mascaradas (ibid. 2010).

De modo a compreendermos como essas estratégias de organização se dão dentro de uma composição saturista iremos abordar a peça Graphein ${ }^{11}$, de Raphael Cendo, escrita em 2014 para flauta baixo/flauta/piccolo; clarinete/clarinete baixo; saxofone alto/soprano/tenor; trompa; harpa; percussão; piano; violino; violoncelo; contrabaixo. A peça é, segundo seu autor, “a síntese de dez anos de pesquisa sobre os sons complexos".

\section{Graphein}

Uma das maiores dificuldades ao se realizar análises sobre obras que fazem uso ostensivo de sonoridades advindas do uso de técnicas estendidas, assim como de sonoridades ruidosas e saturadas, deriva do fato de a partitura representar pouco do fenômeno sonoro resultante. Estamos diante de casos nos quais "não há uma simples correspondência de um-para-um entre a partitura e o fenômeno [sonoro]" (Thoresen et al. 2007). Sendo assim, procuramos desenvolver procedimentos de análises que pudessem suplantar as dificuldades inerentes ao estudo dessas obras, oferecendo novos modelos de visualização e compreensão acerca do agenciamento dos materiais musicais presentes nessas obras. Para tal, nossa análise fez uso de um conjunto de estratégias que, além do estudo realizado diretamente sobre a partitura, fizeram uso de: (1) análise aural de fonogramas, assim como proposta por Lasse Thoresen (ibid.) ${ }^{12}$; (2) análise de

\footnotetext{
${ }^{11}$ Para a análise aural e análise através de descritores de áudio usamos a gravação realizada pelo Ensemble Linea e disponível em $<$ https://www.youtube.com/watch? $\mathrm{v}=$ oxDFyTdeDPA $>$. Último acesso realizado em 29/08/2021.

${ }_{12}$ Essa proposta analítica que "substitui consistentemente a partitura pelo fonograma enquanto o suporte material extra-temporal das reflexões analíticas" (Thoresen et al. 2007), centra-se nas intenções e capacidades perceptivas do analista/ouvinte e propõe três níveis de investigação
} 
formas de onda e sonogramas; (3) análise de parciais via FFT (4) análise realizada por descritores de áudio ${ }^{13}$.

\subsection{Procedimentos de análise}

A análise foi realizada através dos seguintes procedimentos (1) estudo da partitura; (4) análise aural do fonograma; (5) segmentação da obra a partir da identificação aural dos objetos, texturas e gestalts que sustentam a obra; (6) análise do áudio através do uso de descritores de áudio; (7) classificação dos segmentos a partir de suas características morfológicas; (8) análise dos segmentos a partir da identificação dos recursos técnicos ou estéticos apresentados pelo compositor em seus textos. Tal metodologia buscou criar um procedimento de análise que pudesse dar conta da obra de um autor cujos preceitos propõem: (1) compor visando a uma desorientação integral (Cendo 2008); (2) criar obras que se recusam a serem submetidas aos processos de análise que se organizaram "em torno de um pensamento controlado, paramétrico e microscópico da escritura" (ibid. 2010).

\subsection{Segmentação}

Nos processos de segmentação da obra em blocos de sonoridade, classificamos os segmentos a partir dos seguintes parâmetros: (1) saturação/infra-saturação; (2) uso do efetivo instrumental; (3) presença de gestos e gestalts direcionais; (4) justaposição acelerada de comportamentos contrastantes (5) predominância de alturas definidas (6) texturas contínuas; (7) texturas descontínuas. Alguns desses grupos ainda podem conter outras divisões, como detalhado a seguir:

baseadas na identificação, classificação e descrição de material sônico. São eles: (1) nível do objeto sonoro; (2) nível das gestalts elementares: combinação de objetos sonoros em pequenas gestalts; (3) nível das gestalts formais: padrão das gestalts elementares.

${ }^{13} \mathrm{O}$ uso ferramentas composicionais torna-se extremamente útil em análises realizadas em obras nas quais a partitura pode "não ser suficiente para a compreensão macro e micro estrutural do universo sonoro no qual o compositor está inserido [...] nesses casos [...] os ambientes computacionais possibilitam novas técnicas de análise musical e recuperação da informação musical" (Simurra 2018, p. 34). 
- Saturação/Infra-Saturação: aqui foram usados os seguintes parâmetros propostos por Cendo: (1) saturação do timbre; (2) saturação da intensidade; (3) saturação do gesto instrumental (ibid.). Ainda no que diz respeito à infrasaturação, fizemos da ideia de granulação e velocidade de grãos, que consiste no estiramento ou compressão dos materiais em suas projeções no tempo (ibid. 2010).

- Uso do efetivo instrumental: aqui podemos identificar as seguintes possibilidades (1) tutti; (2) formações camerísticas; (3) formação camerística com predominância de figurações solísticas.

- Gestos e gestalts direcionais: essa categoria pode ser dividida em processos direcionais de curta e média duração, indo de gestos rápidos em anacruse até estruturas gestálticas de até 2 minutos de duração.

Na Tab. 1, apresentada abaixo, podemos verificar como os grupos e subgrupos se instituem.

\begin{tabular}{|c|c|c|c|}
\hline Grupo & \multicolumn{2}{|c|}{ Sub Grupo } & do gesto \\
\hline Saturação/infra-saturação & do timbre & da intensidade & \\
\hline Efetivo instrumental & em tutti & em formações camerísticas & \\
\hline Gestos e gestalts direcionais & $\begin{array}{c}\text { de curta } \\
\text { duração }\end{array}$ & de média duração & \\
\hline $\begin{array}{c}\text { Justaposição blocos de } \\
\text { sonoridades contratantes }\end{array}$ & rápida & \\
\hline $\begin{array}{c}\text { Predominância de alturas } \\
\text { definidas }\end{array}$ & & \\
\hline $\begin{array}{c}\text { Texturas } \\
\text { contínuas/discontínuas }\end{array}$ & & \\
\hline
\end{tabular}

Tabela 1: Grupos e subgrupos encontrados em Graphein.

Tais categorizações não são excludentes, mas apresentam-se combinadas de forma a caracterizar os blocos de sonoridade da peça. Como exemplo podemos citar: (1) gestos direcionais curtos em tutti apresentando saturação de energia; (2) infra-saturação do gesto, com alongamento do grão e saturação do timbre; (3) infra-saturação da dinâmica e saturação do gesto instrumental. 


\subsection{Processos de elaboração}

No que diz respeito ao agenciamento desses materiais na elaboração da obra podemos encontrar três recursos que determinam suas projeções no tempo. São eles: (1) oposição entre concentração e dispersão de energia; (2) justaposição de blocos sonoros de características contrastantes; (3) elaboração de estruturas simétricas. Tais recursos são encontrados em três níveis de organização, estando presente tanto na elaboração das seções, na elaboração das subseções e na organização dos eventos internos dos blocos.

\subsection{Oposição entre concentração e dispersão de energia}

Iremos apresentar um trecho de Graphein, presente na parte final da obra que consiste em uma grande saturação do timbre e da dinâmica, realizada pelas madeiras, trompa, vibrafone, harpa e piano e que se interrompe bruscamente por um ataque em fff no piano e na percussão, tendo sua energia dispersada tanto através da ressonância do piano e do vibrafone quanto da transferência dessa energia para as cordas, que realizam uma textura de harmônicos em trêmolo e glissandos. Para finalizar essa dispersão, temos um resquício da energia sendo transferida para o piccolo, que realiza um som ruidoso e aerado. De forma a demonstrarmos as características dessa oposição, iremos abordar análises feitas a partir de: (1) descritores de áudios referentes ao loudness, harmonic energy e spectral perceptual centroid; (2) sonograma e partial tracking; (3) análise da partitura. Nas Figs. 1 e 2 podemos verificar como se dá essa dispersão a partir do uso de dois descritores de áudio, a saber: o perceptive loudness e o harmonic energy.

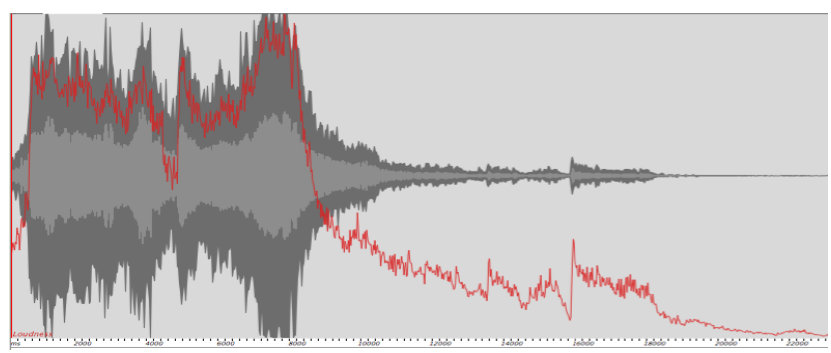

Figura 1: Análise do Loudness do excerto de Graphein que se inicia em 13 minutos e 11 segundos. 
MUSICA THEORICA Revista da Associação Brasileira de Teoria e Análise Musical 2021, v. 6, n. 1, p. 192-217 - Journal of the Brazilian Society for Music

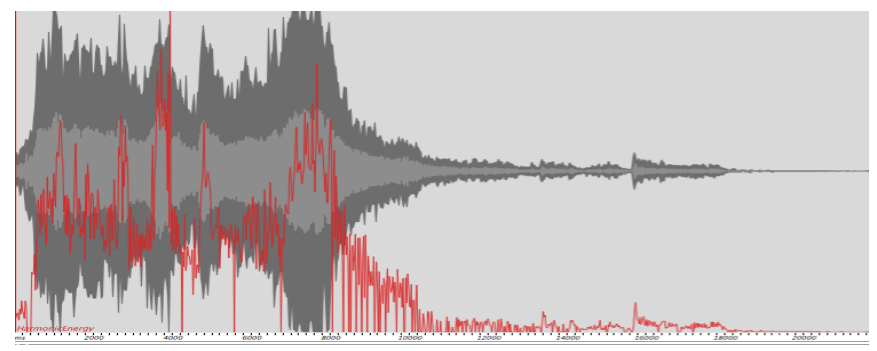

Figura 2: Análise de harmonic energy do excerto de Graphein que se inicia em 13 minutos e 11 segundos.

Nas Figs. 3 e 4, podemos visualizar duas análises realizadas com o software Audio Sculpt, aqui estão representados, respectivamente, o sonograma do excerto, e a análise dos parciais presentes nessa estrutura gestáltica. $\mathrm{Na}$ análise dos parciais podemos perceber, a saturação frequencial advinda do uso das técnicas estendidas mesmo quando há uma dispersão do material.

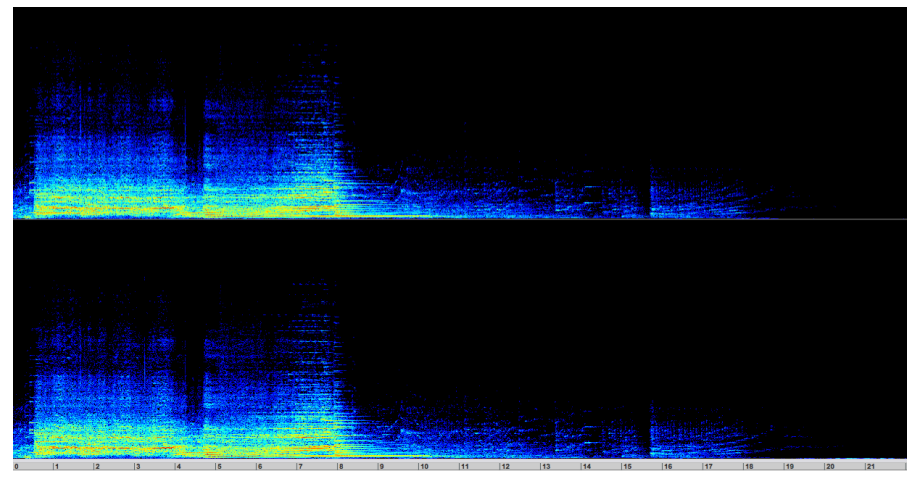

Figura 3: Sonograma do excerto de Graphein que se inicia em 13 minutos e 11 segundos.

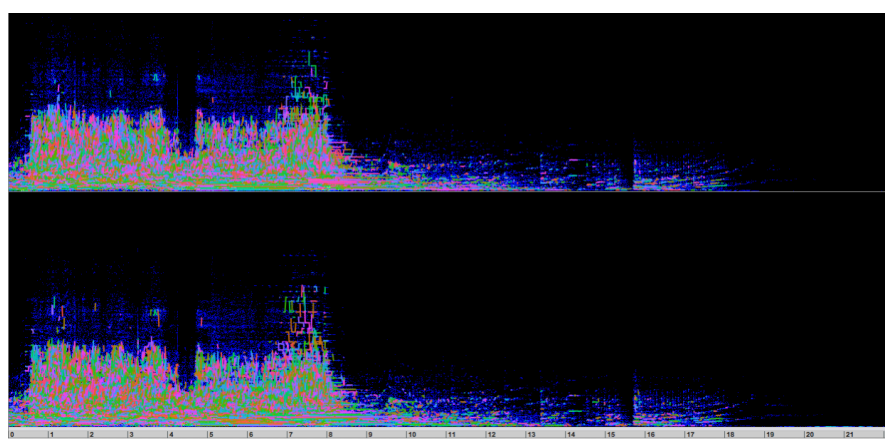

Figura 4: Análise dos parciais do excerto de Graphein que se inicia em 13 minutos e 11 segundos.

Para finalizar, na Fig. 5 podemos visualizar a análise da spectral perceptual centroid. 


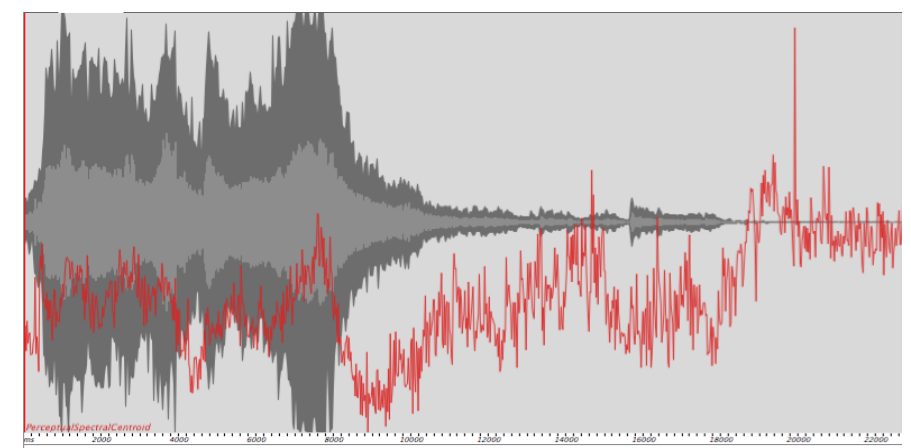

Figura 5: Análise de spectral perceptual centroid do excerto de Graphein que se inicia em 13 minutos e 11 segundos (c. 268 a 276 da partitura).

Ao cruzarmos as análises apresentadas nas figuras acima, verificamos que: (1) ao jogo de concentração e dispersão de energia, corresponde um jogo de concentração e dispersão de material frequencial harmônico: ou seja quanto mais energia o material sonoro apresenta, mais energia harmônica se apresenta; (2) inversamente à diminuição dos valores referentes ao loudness e harmonic energy, verificamos um aumento dos valores da spectral perceptual centroid: que esse passa a assumir a condução do discurso musical, antes delegada aos níveis de energia e material frequencial harmônico; (3) a esses dois jogos de oposição, podemos verificar um jogo de oposição no âmbito do efetivo instrumental, que opõe as madeiras e percussão às cordas.

\subsection{Justaposição de blocos sonoros de características contrastantes}

Esse recurso é amplamente explorado em Graphein, sendo determinante nos processos de elaboração formal e nos processos de elaboração de estruturas locais. Nas figuras abaixo, podemos visualizar um excerto consistindo de sete blocos cujas principais características são: (1) gesto estatisticamente ascendente (como pode ser verificado na partitura, são figurações que se desenvolvem ascendentemente no registro), envolvendo todo o ensemble instrumental apresentando saturações do gesto e da dinâmica; (2) ataques em ff bastante marcados e regulares que se transferem entre grupos instrumentais não homogêneos; (3) som saturado sustentado; (4) gesto em clusters extremamente granulado na região aguda do piano de caráter adirecional; (5) ataque no bumbo sinfônico transmutando o caráter da textura pianística de adirecional para ondulatória; (6) finalização do gesto com um direcionamento da textura granular 
MUSICA THEORICA Revista da Associação Brasileira de Teoria e Análise Musical 2021, v. 6, n. 1, p. 192-217 - Journal of the Brazilian Society for Music

do piano para a região grave juntamente com a dissipação total da energia. Nas figuras abaixo podemos visualizar essa passagem através de análises via descritores de áudio e sonograma.

Nas Figs. 10 e 11, podemos ver na partitura de Graphein um excerto que vai do compasso 130 ao compasso 138. Nessa visualização podemos verificar que essa alternância de blocos se dá, no âmbito da escrita, de maneira bastante clara. Sendo assim, os blocos 1, 2 e 3 estão nos compassos 130, 131 e 132 consecutivamente; bloco 4 nos compassos 133, 134 e metade do 135; bloco 5 a partir da metade do compasso 135 até o compasso 137 e finalmente, o bloco 6 tem início no último tempo do compasso 137 e se estende até o compasso 139 (que não aparece em nossa figura).

Na Fig. 6, podemos visualizar o sonograma da gravação referente aos compassos 130 a 139 esses compassos com marcas acrescentadas nas mudanças de blocos. Nas Figs. 7, 8 e 9 podemos verificar as análises dos seguintes descritores de áudio: (1) perceptual spectral centroid; (2) loudness; (3) harmonic energy.

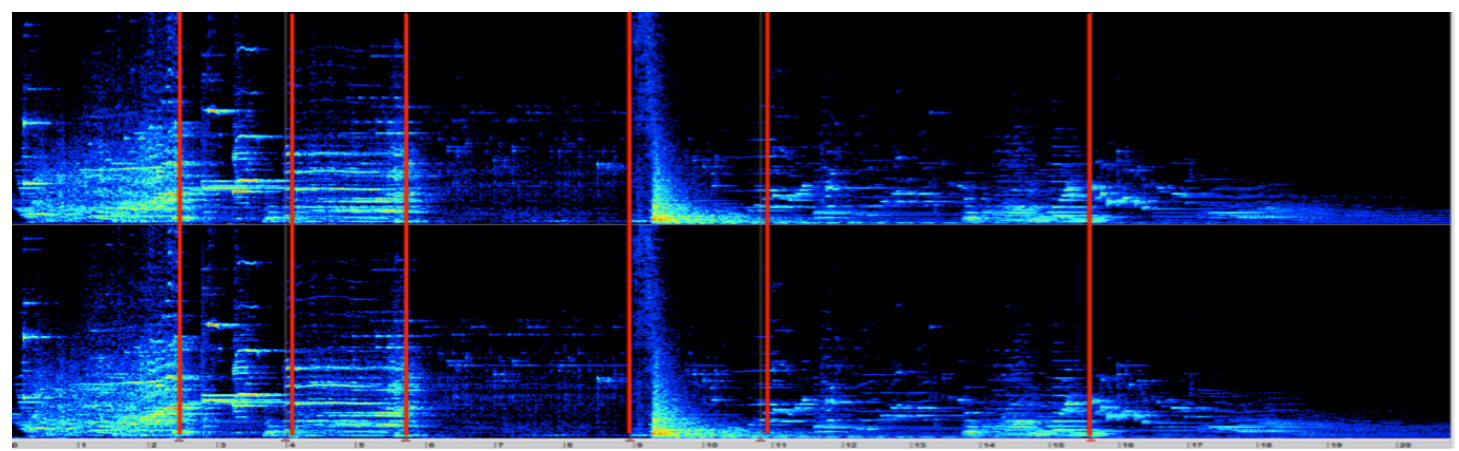

Figura 6: Sonograma de um excerto da gravação de Graphein referente aos compassos 130 a 138.

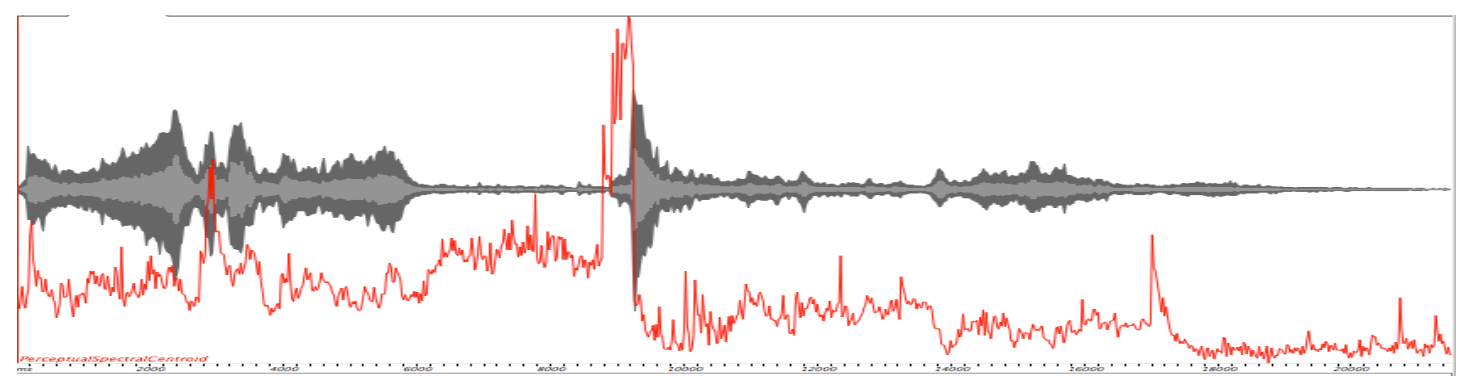

Figura 7: Análise de spectral perceptual centroid de um excerto da gravação de Graphein referente aos compassos 130 a 138 da partitura. 


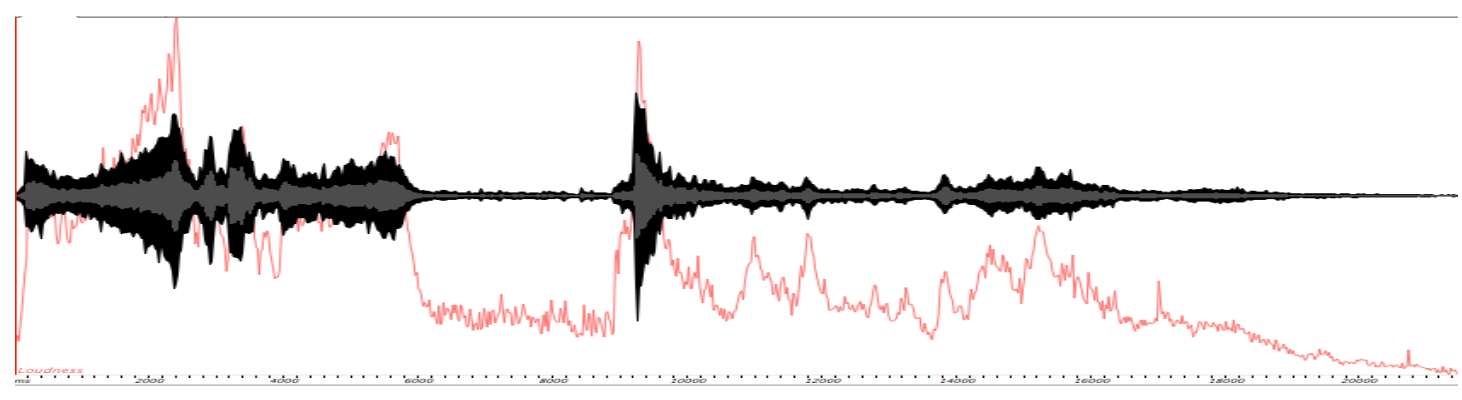

Figura 8: Análise de loudness de um excerto da gravação de Graphein referente aos compassos 130 a 138 da partitura.

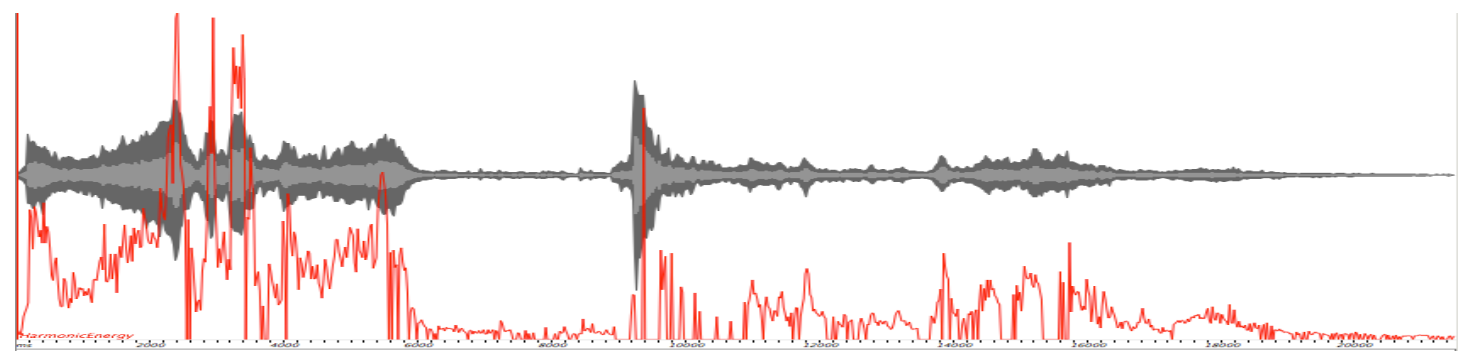

Figura 9: Análise de harmonic energy de um excerto da gravação de Graphein referente aos compassos 130 a 138 da partitura.

Analisando cada uma dessas imagens e cruzando as informações obtidas podemos verificar que: (1) as mudanças dos espectros dos blocos assim como os comportamentos desses espectros ficam bastante evidentes tanto na imagem do sonograma quanto nas análises dos descritores de áudio; (2) o bloco 2 contém os maiores valores de energia harmônica; (3) os valores da spectral perceptual centroid tendem a ser mais altos nos blocos de infra-saturação dinâmica; (4) um evento saliente bem no meio do excerto que comporta os valores mais altos da spectral perceptual centroid, do loudness e da energia harmônica.

\subsection{Elaboração de estruturas simétricas}

O uso de estruturas simétricas em Graphein é bastante recorrente, e assim como os outros recursos abordados nessa seção, aparecem tanto nos níveis microestruturais quanto nos macroestruturais. Tais simetrias se dão através de comportamentos texturais, comportamentos dinâmicos e proporções temporais.

Iremos demonstrar agora como tais processos são responsáveis pela elaboração da peça tendo como exemplo as estruturas presentes na primeira seção da peça. Macro estruturalmente ela consiste em uma oposição entre um momento de saturação e um momento de infra-saturação. Na Fig. 10, podemos 
MUSICA THEORICA Revista da Associação Brasileira de Teoria e Análise Musical 2021, v. 6, n. 1, p. 192-217 - Journal of the Brazilian Society for Music

visualizar em sonograma tal oposição simétrica, no qual fica bastante evidente a simetria temporal de ambas as subseções.

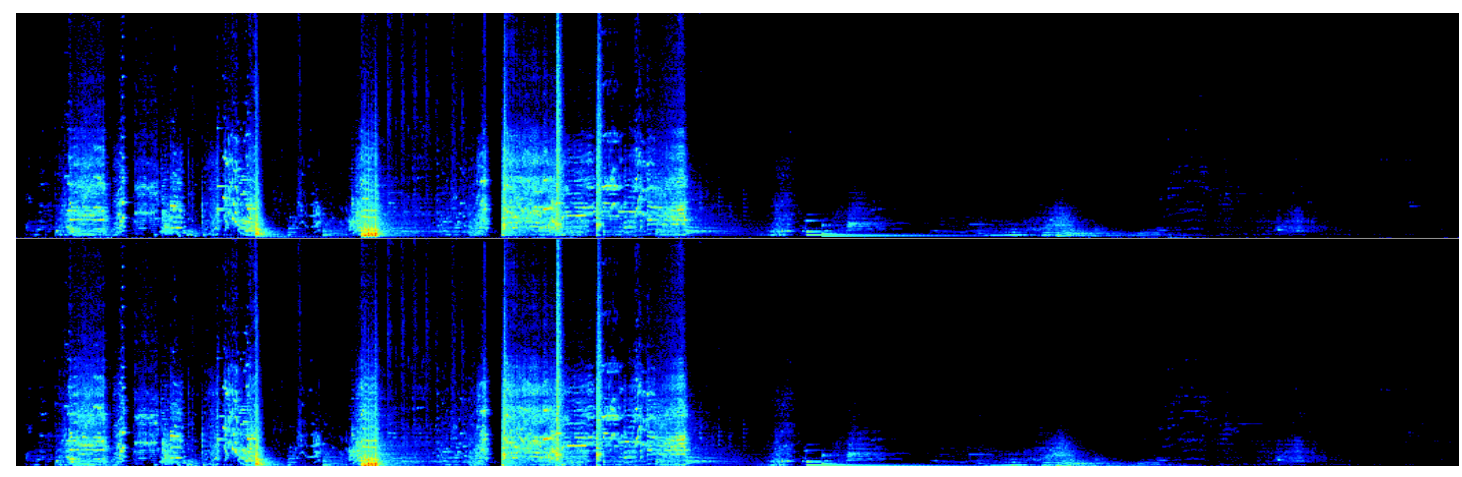

Figura 10: Sonograma referente aos primeiros 2 minutos e 21 segundos de Graphein.

Se adentramos nas subseções, podemos perceber que elas também são organizadas a partir de um princípio de simetria. Na Fig. 11, podemos visualizar uma representação da forma de onda da primeira subseção desse trecho na qual ficam evidenciados os seguintes elementos de simetria: (1) um evento saliente marcando a metade da seção; (2) este evento saliente, de caráter saturado, está antecedido e procedido de uma situação de infra-saturação da dinâmica; (3) durações dos eventos que antecedem e sucedem o evento salientado possuem durações muito próximas.

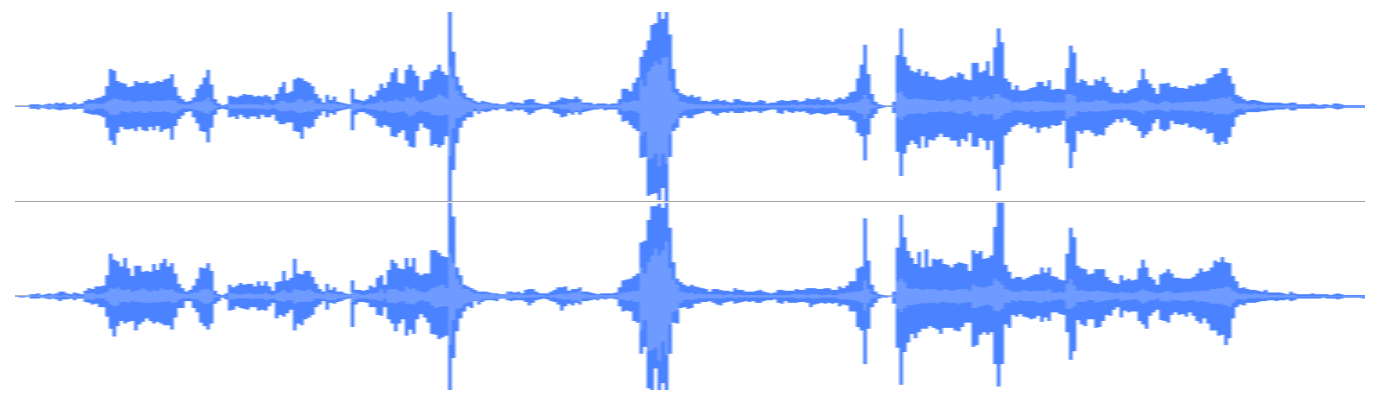

Figura 11: Forma de onda referente aos primeiros 2 minutos e 21 segundos de Graphein.

Ao sobrepormos a forma de onda ao sonograma, como podemos verificar na Fig. 12, outros aspectos da estrutura se evidenciam. De forma a melhor compreendermos as características estruturais dessa seção, dividimos esta seção em quatro subseções cujas características são: (1) justaposição de blocos contrastantes; (2) infra-saturação momentânea no qual é possível identificar uma saliência da spectral perceptual centroid delimitando a metade da subseção (ver Fig. 13); (3) infra-saturação da dinâmica associada a saturação da dinâmica e da 
sonoridade; (4) saturação do timbre e da dinâmica. É preciso ressaltar que as seções 3 e 4 possuem uma textura com ataques em proporções regulares. Contrariamente, as seções 1 e 2 são construídas a partir de comportamentos rítmicos não regulares.

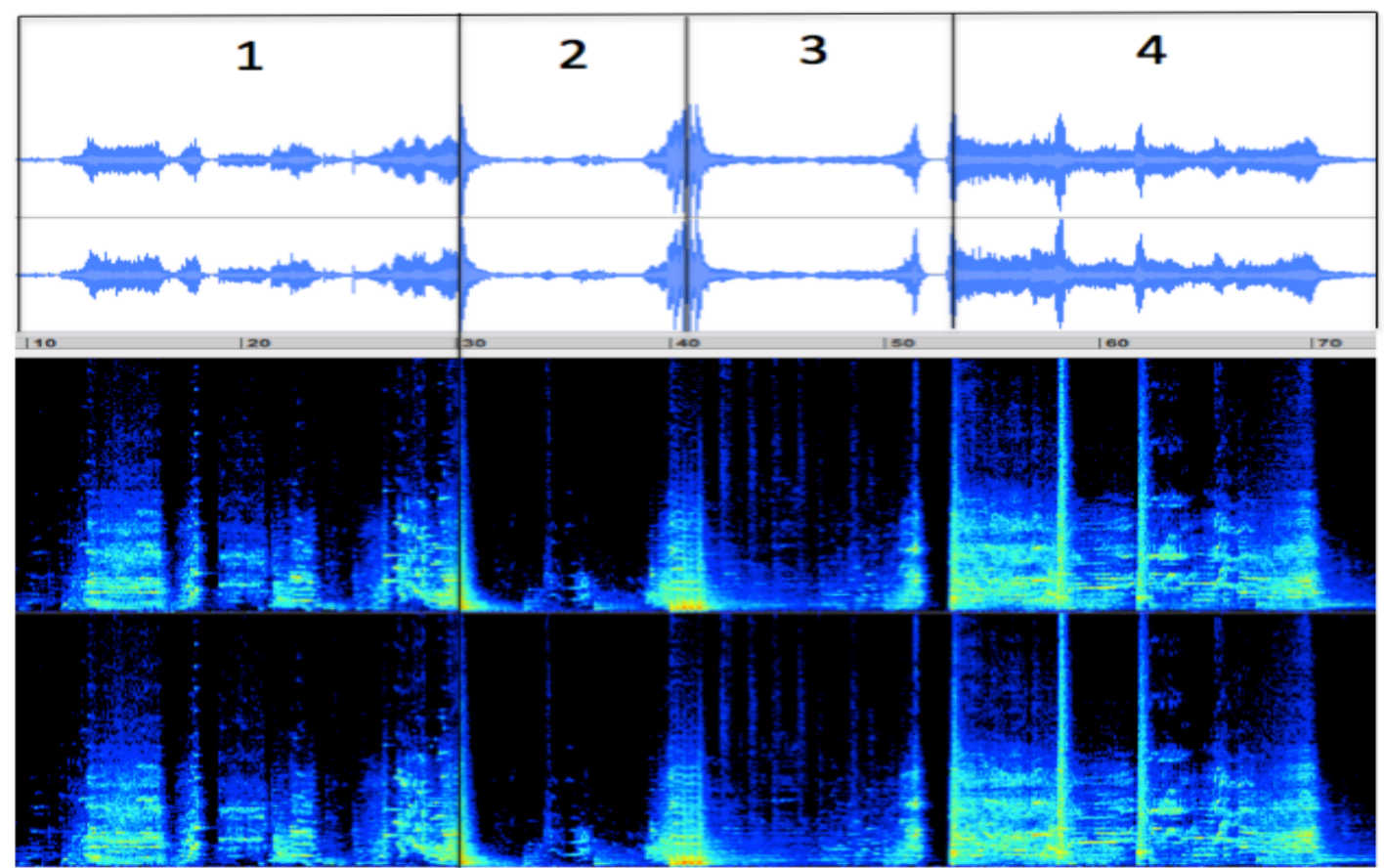

Figura 12: Forma de onda e sonograma com marcas referentes aos primeiros 2 minutos e 21 segundos de Graphein.

Nas Figs. 13 e 14, duas imagens representando análises da spectral perceptual centroid e harmonic energy nas quais podemos extrair outros dados que nos ajudam a compreender o jogo de elaboração.

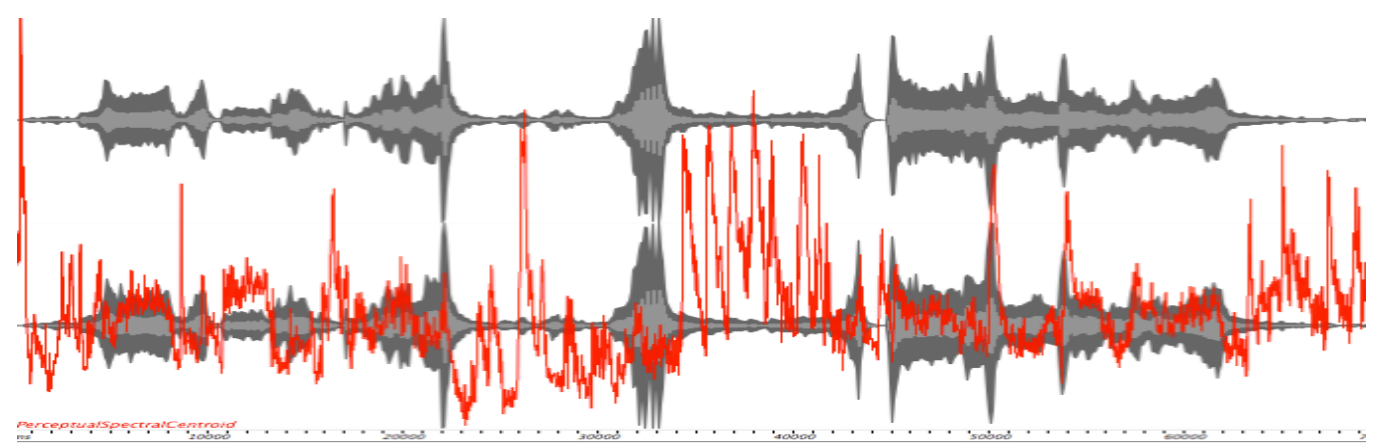

Figura 13: Análise de spectral perceptual centroid referente aos primeiros 2 minutos e 21 segundos de Graphein. 


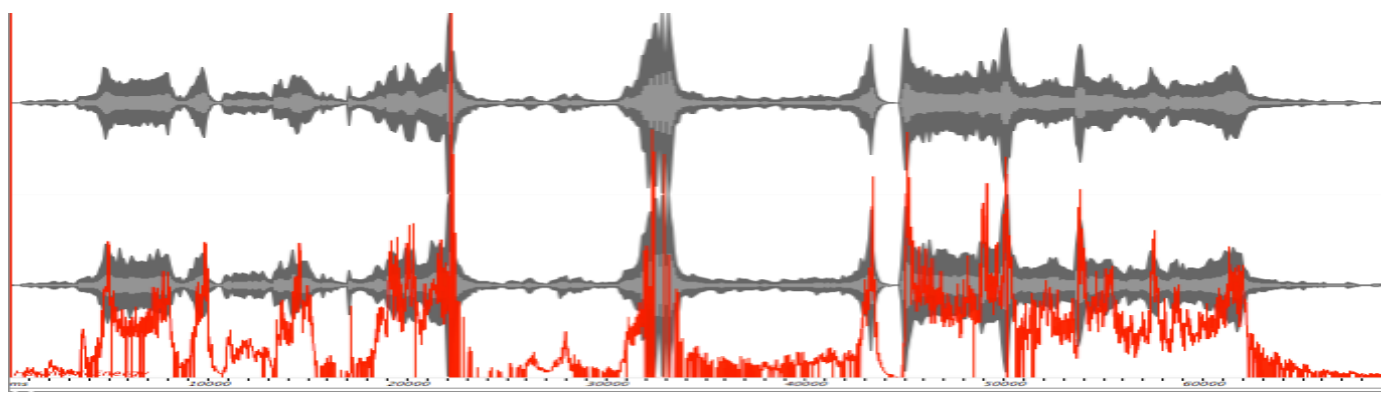

Figura 14: Análise da energia harmônica referente aos primeiros 2 minutos e 21 segundos de Graphein.

Nessas duas imagens ficam evidenciados: (1) os ataques regulares da subseção 3 são realizados por sonoridades aeradas, e portanto apresentam picos nos valores da spectral perceptual centroid; (2) o jogo de infra-saturação da dinâmica - evidenciado através dos valores baixos das energias harmônicas - e da saturação do timbre na subseção 3 assim como na finalização da subseção 4 evidenciado pelos valores altos da spectral perceptual centroid; (3) o jogo de justaposição de blocos contrastantes na subseção 1, evidenciado pelas mudanças abruptas nos valores da spectral perceptual centroid e das energias harmônicas; (4) o evento saliente da subseção 2 evidenciado pelo pico do valor da spectral perceptual centroid, assim como estava sendo sugerido pela imagem do sonograma.

Para finalizar, apresentamos na Fig. 15 o sonograma - acrescido de marcas evidenciando os ataques -, contendo o último bloco da subseção 1 e as subseções 3 e 4. Aqui, podemos verificar uma clara elaboração envolvendo a dilatação progressiva das distâncias que compõem os ataques regulares. Tal elaboração se resolve, na finalização da subseção 4 com a compressão e desestabilização das regularidades dos ataques.

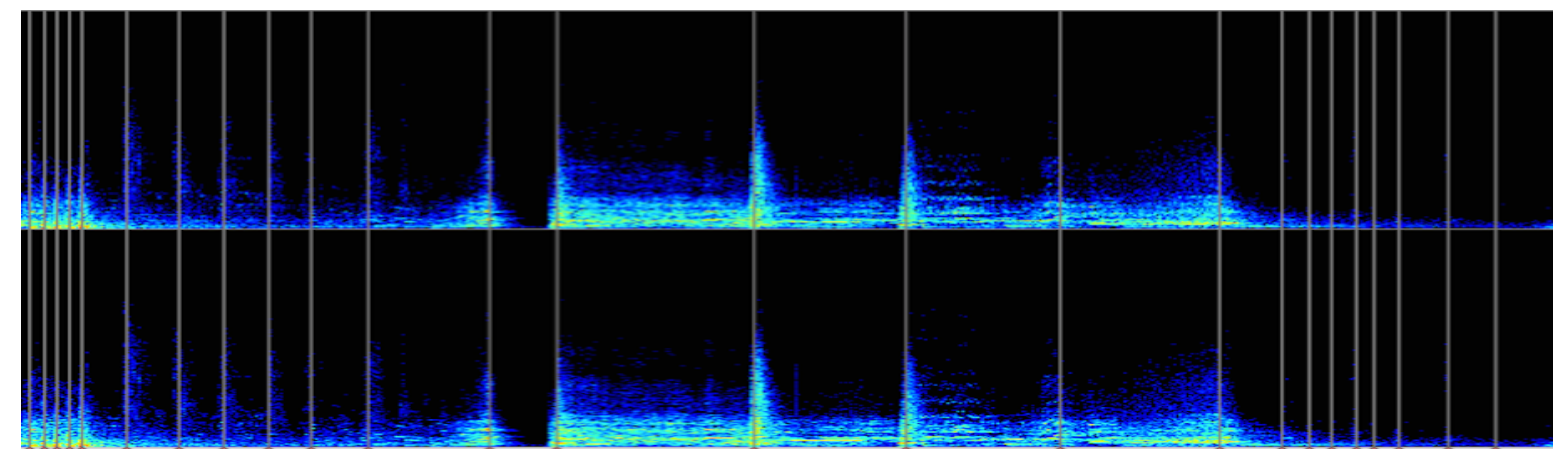

Figura 15: Análise da energia harmônica referente aos primeiros 2 minutos. 


\subsection{Estrutura Formal}

A forma de Graphein, que apresenta sete seções, se constrói a partir dos jogos de justaposição e sobreposição estabelecidos entre os diversos recursos de construção apresentados nesse artigo. Para definirmos a estrutura formal, assim como classificar os segmentos analisados da peça, levamos em conta: (1) pregnância de materiais e seus comportamentos de organização; (2) introdução de novos materiais e/ou comportamentos; (3) articulação dos segmentos através do uso prolongado do silêncio. Na Fig. 16, podemos visualizar um mapa, realizado em um programa de edição de áudio, contendo os segmentos que compõem e definem a estrutura formal. De forma a visualizarmos os jogos de justaposição e sobreposição desses segmentos, segmentamos o arquivo de áudio conforme seus comportamentos sonoros característicos, e os alocamos em diferentes tracks. Sendo assim, a distribuição dos comportamentos nos tracks se apresenta da seguinte maneira:

- Pista 1: segmentos caracterizados pela saturação do timbre e da dinâmica;

- Pista 2: segmentos caracterizados pela saturação do gesto;

- Pista 3: segmentos caracterizados pela infra-saturação sem estiramento do grão;

- Pista 4: segmentos caracterizados pela infra-saturação e estiramento do grão;

- Pista 5: segmentos caracterizados por texturas distendidas no hiperagudo;

- Pista 6: segmentos caracterizados por gestos direcionais;

- Pista 7: segmentos caracterizados pela justaposição de blocos;

- Pista 8: segmentos caracterizados por ataques isorrítmicos;

- Pista 9: segmentos caracterizados por figurações solísticas;

- Pista 10: segmentos caracterizados por notas longas de altura definida;

- Pista 11: segmentos caracterizados pela articulação de eventos através de ataques nos gongos. 


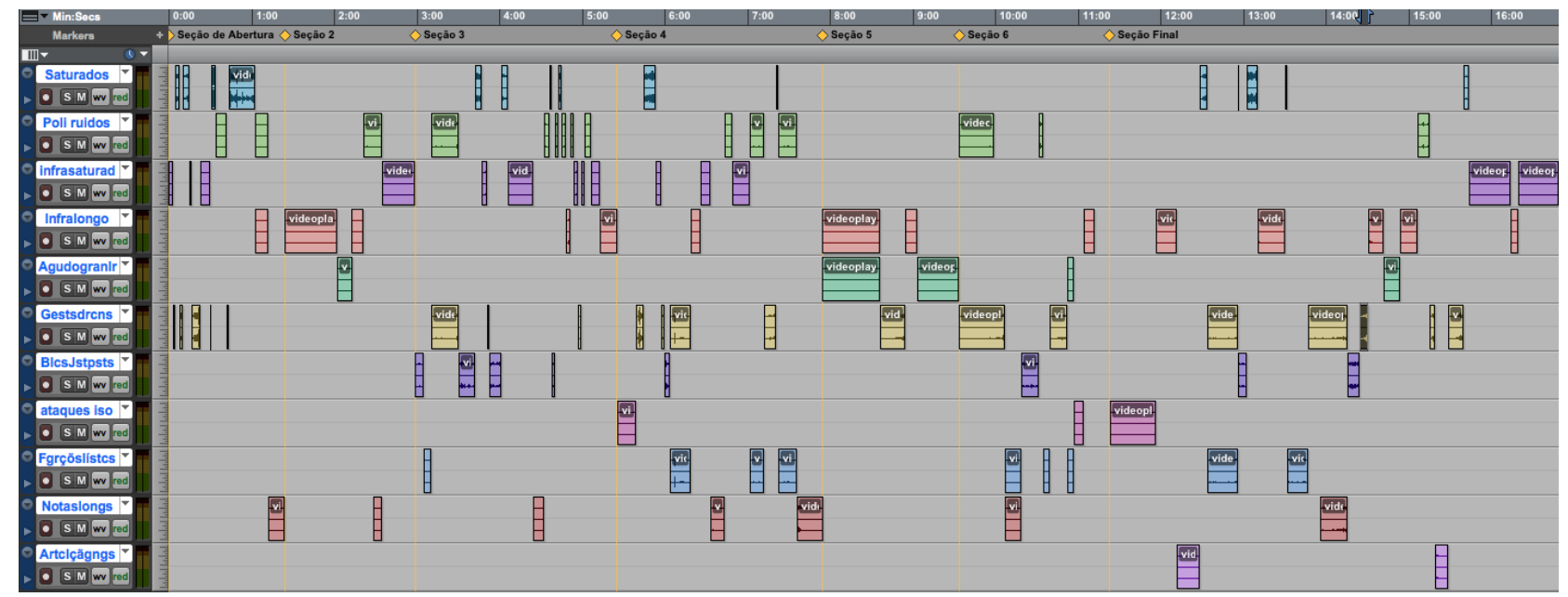

Figura 16: Mapa dos eventos e da estrutura formal de Graphein.

\section{Considerações Finais}

Tendo em vista que nossa pesquisa teve como foco compreender como se dão os processos de elaboração em obras que fazem uso de sonoridades estendidas, as análises apresentadas aqui se instituem enquanto caminhos possíveis para compreendermos as forças que estão em jogo em obras que têm como material sonoro os sons complexos e saturados advindos das técnicas estendidas.

Para finalizar, no parece ainda relevante realçar a ideia de que Cendo, bem como outros compositores como os que citamos ao longo deste artigo, compreende a composição de sons complexos como intimamente relacionada à composição orientada por gestos instrumentais, muitas vezes abdicando de uma organização explícita no campo das alturas e adotando uma notação de orientações motoras para os instrumentistas. Nesse caso, o que se visa como resultado final não é uma altura definida, mas um determinado fluxo de energia que estaria compreendido na evolução complexa de um som. Tal aspecto ficounos claro ao identificarmos os três princípios composicionais preponderantes no decorrer da peça, a saber: o contraste, a dispersão ou contração, e a simetria, que 
se encontram todos relacionados aos fluxos de energia de determinados gestos ${ }^{14}$. Sendo assim, o uso de descritores de áudio nos possibilitou verificar a velocidade e a densidade de transformação de dados como centróide, densidade espectral e variação espectral presentes no resultado sonoro de um determinado gesto evidenciando como as estratégias composicionais baseadas nesses fluxos de energia se instituem.

Por fim, compreendemos que um pensamento composicional que tenha tais indicadores de complexidade dinâmica de um som permite uma diversidade de estratégias composicionais a serem exploradas, talvez trazendo para o universo da escrita instrumental e da chamada síntese instrumental aspectos desenvolvidos por compositores dos anos 1960, como György Ligeti, ou dos anos 1970, como em Grisey ou Murail, para um universo complexo da escrita instrumental a partir da ideia de gesto.

\section{Referências Bibliográficas}

1. Artaud, Pierre-Yves. 1995. Present day flutes. Paris: Billaudot.

2. Bok, Henry. 1989. New techniques for bass clarinet. Rotterdam: HBok.

3. Cendo, Raphael. 2008. Les paramètres de la saturation. Disponível em: <http://brahms.ircam.fr/documents/document/21512/>.

4. __. 2010. Saturation Instrumentale: organization et nouveuaux enheux pour la composition para Raphael Cendo. Disponível em:

$<$ http://www.cdmc.asso.fr/fr/content/saturation-instrumentale-organisation-etnouveaux-enjeux-pour-la-composition-par-raphael>. Último acesso em: 29/08/2021.

5. __. 2011. Excès de geste et de matiére: la saturation comme modèle compositionnel. Disponível em:

$<$ https://www.dissonance.ch/fr/archives/articles de fond/876/abstract/fr $>$. Último acesso em: 29/08/2021.

\footnotetext{
${ }^{14}$ Entendemos por fluxo de energia o envelope dinâmico e o índice de transformação acústica das resultante sonoras dos gestos e que são evidenciados quando nos valemos de descritores de áudio
} 
6. Dempster, Stuart. 1994. The modern trombone. Bloomington: Indiana University Press.

7. Dolak, Fritz. 1980. Contemporary techniques for the clarinet. New York: Studio.

8. Gieseler, Walter; Lombardi, Luca; Weyer, Rolf. 1985. Instrumentation in des 20 Jahrhunderts: Akustik - Instrumente - Zusammenwirken. Berlin: Moeck.

9. Hill, Douglas. 1983. Extended tecchniques for the horn. New York: Warner Music.

10. Meyer, Jürgen. 2009. Acoustics and the performance of music. New York: Srpinger.

11. Penazzi, Sergio. 1989. Metodo per fagotto. Milão: Suvini Zerboni.

12. Pustijanac, Ingrid. 2016. New Graphic Representation for Old Musical Experience: Analyzing Improvised Music. El oído pensante, v. 4, n. 1.

13. Read, Gardner. 1998. Compendium of Modern Instrumental Techniques. Connecticut: Greenwood.

14. Rigaudière, Pierre. 2014. La saturation, métaphore pour la composition? Circuit: musiques contemporaines, v. 24, n. 3, p. 37-50.

15. Robert, Jean-Pierre. 1994. Modes de jeu de la contrebasse. Paris: Musica Guild.

16. Simurra, Ivan E. 2018. Análise Musical Assistida por Descritores de Áudio: um estudo de caso da obra Reflexões de Jônatas Manzolli. Musica Theorica, v. 3, n. 1, p. 33-67.

17. Solomos, Makis. 2013. De la musique au son. L'émergence du son dans la musique des XXe-XXIe siècles. Ehesp: Presses universitaire de Rennes.

18. Thoresen, Lasse; Hedman, Andreas; Thommessen, Olav. 2007. Form-Building Transformations: An Approach To The Aural Analysis Of Emergent Musical Forms. The Journal of Music and Meaning, v. 4, section 3. Disponível em: $<$ http://www.musicandmeaning.net/issues/showArticle.php?artID=4.3 $>$. Último acesso em: 29/08/2021.

19. Zampronha, Edson. 2000. Notação, representação e composição: um novo paradigma da escritura musical. São Paulo: Annablume. 